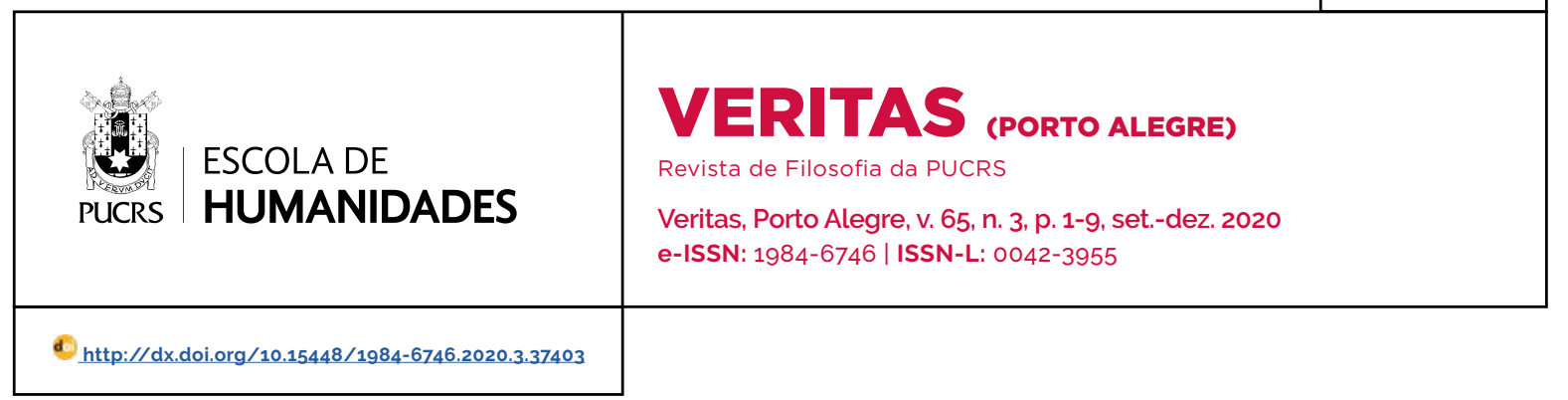

SEÇÃO VARIA

\title{
La liberación del reconocimiento
}

The liberation of recognition

\section{A liberação do reconhecimento}

\section{Agustin Lucas Prestifilippo $^{1}$ \\ orcid.org/0000-0002-4199-2478 alprestifilippo@gmail.com}

Fábio Caires Correia ${ }^{2}$ orcid.org/0000-0002-1768-3720 juanfabiogestor@gmail.com

Recibido en: 19/03/2020. Aprobado en: 05/07/2020. Publicado en: 12/01/2021.

\section{(c) (i)}

Artigo está licenciado sob forma de uma licença Creative Commons Atribuição 4.0 Internacional.
Resumen: La Teoria Critica contemporánea presenta un curioso movimiento Mientras que, por un lado, solicita las categorías de Marx para dar cuenta del fenómeno reciente de la crisis del capitalismo neoliberal; al mismo tiempo, reconoce que esa teoría no puede decirlo todo, requiriendo de un acercamiento de su perspectiva hacia objetos y problemas ajenos, acaso obstruidos por los limites al interior de los cuales se habria desplazado su pensamiento. Una de las fuentes de inspiración más poderosas de este movimiento de ampliación cuyo saldo no es sino una verdadera heteroglosia filosófica, se encuentra en la teoria del espíritu del idealismo alemán, más precisamente en sus modulaciones hegelianas. El regreso a Hegel vendria motivado por la necesidad de indagar, como se observa en la obra de Axel Honneth, en los dilemas de los vínculos humanos en un mundo social signado por el fenómeno de la fragmentación. En este escrito nos detendremos en analizar algunos elementos de un reciente debate al interior de la Teoria Crítica contemporánea acerca del problema de la articulación entre reconocimiento y libertad, reconstruyendo las distintas estrategias de lectura de Hegel que aqui se ponen en movimiento.

Palabras clave: Teoria Crítica contemporánea, Hegel, Reconocimiento, Libertad, Axel Honneth.

Resumo: A Teoria Crítica contemporânea apresenta um curioso movimento. Ainda que, por um lado, solicita as categorias de Marx para dar contra do fenômeno recente da crise do capitalismo neoliberal, ao mesmo tempo, reconhece que essa teoria não pode dizer tudo, exigindo uma abordagem de sua perspectiva em relação a objetos e problemas outros, talvez obstruida pelos limites dentro dos quais seu pensamento teria se movimentado. Uma das fontes de inspiração mais poderosa deste movimento de ampliação, cujo saldo não é senão uma verdadeira heteroglossia filosófica, se encontra na teoria do espirito do idealismo alemão, mais precisamente em suas modulações hegelianas. O retorno a Hegel seria motivado pela necessidade de investigar, como se observa na obra de Axel Honneth, os dilemas dos vínculos humanos em um mundo social marcado pelo fenômeno da fragmentação. Neste artigo dos deteremos em analisar alguns elementos de um recente debate no interior da Teoria Critica contemporânea sobre o problema da articulação entre reconhecimento e liberdade, reconstruindo as diferentes estratégias de leitura de Hegel que aqui são postas em movimento.

Palavras-chave: Teoria Crítica contemporânea; Hegel; Reconhecimento; Liberdade; Axel Honneth.

Abstract: Contemporary Critical Theory presents a curious movement. While on the one hand it requests Marx's categories to account for the recent phenomenon of the crisis of neoliberal capitalism, at the same time it recognizes that this theory cannot say everything, calling for an approach of its perspective towards different objects and problems, perhaps hindered by the limits within which its thought would have moved. One of the most powerful sources of inspiration for this movement of enlargement, the result of which is nothing but a true philosophical heteroglossia, is found in the theory of the spirit of German idealism, more precisely in its Hegelian modulations. The return to Hegel would be motivated 
by the need to investigate, as can be seen in Axel Honneth's work, the dilemmas of human bonds in a social world marked by the phenomenon of fragmentation. In this paper we will analyze some elements of a recent debate within contemporary Critical Theory about the problem of the articulation between recognition and freedom, reconstructing the different reading strategies of Hegel that are put in motion here.

Keywords: Contemporary Critical Theory, Hegel, Recognition, Freedom, Axel Honneth.

\section{Introducción}

Desde la publicación de La lucha por el reconocimiento (1992) hasta su última sistematización en base a una reconstrucción diferenciada de sus fuentes histórico-filosóficas en las culturas nacionales de Europa (2018), Axel Honneth ha reformulado de distintas maneras el concepto central de su perspectiva teórica, evidenciando que el mismo sostiene pretensiones de largo alcance. En la medida en que el principio interno de este instrumento teórico tenía que servir a la tarea de "apuntar más allá del horizonte institucional del presente y manifestarse criticamente frente a la forma de dominación política establecida" (Honneth, 1992, p. 13), el "reconocimiento" fue pensado por Honneth programáticamente como un motivo que aspiraba a convertirse en una referencia ineludible para las discusiones que abarcan la comprensión de la lógica y la dinámica implícita en los movimientos y conflictos sociales contemporáneos.

A tales fines, Honneth despliega una estratégia de fundamentación teórica sumamente original que pone en diálogo la categoría marxiana de trabajo con dos perspectivas teóricas heterogéneas a la tradición del materialismo histórico, en las que el autor encontrará la posibilidad de complejizar el enfoque analítico de los procesos de lucha social: la teoria del espíritu del idealismo alemán y la teoría del significado del pragmatismo norteamericano. El concepto de reconocimiento cifra así las posibilidades de una reactualización del legado de la Teoría Crítica de la sociedad de cara a las urgencias teóricas y políticas de los tiempos presentes.

Desde un comienzo, el concepto de "reconocimiento" se compone fundamentalmente de una dimensión constitutiva y de una dimensión normativa. "Reconocimiento" designa, en primer lugar, un conjunto de condiciones sin las cuales las pretensiones de identidad individual y de autorrealización personal no serian realizables en una sociedad. Simultáneamente, para Honneth toda sociedad debe ser entendida como orden institucionalizado de reconocimiento, vale decir: que la sociedad se constituye a sí misma por medio del reconocimiento. Esta formulación del concepto en sentido constitutivo se encuentra, en segundo lugar, imbricada inextricablemente con un contenido normativo, que procede de la atención teórica a la perspectiva en primera persona de los sujetos que actúan.

La apertura de una teoría fundada en el concepto de reconocimiento "al punto de vista normativo desde el que los sujetos evalúan el orden social" (FRASER Y HONNETH, 2003. p. 198) no puede sin embargo asumir aquello que presupusieron las perspectivas utilitarias que, como en el concepto de "interés" de la economía política, le imputaban a los individuos una estructura lógica de comportamiento con presuposiciones atomistas que precisamente volvía impensable la conjunción teórica de subjetividad y sociedad. Para Honneth, el sentido normativo del concepto de reconocimiento se desprende de las "experiencias de injusticia" de los individuos, entendidas como formas de padecimiento motivadas por la percepción de una injustificada negación del reconocimiento de "cualidades o capacidades de los afectados", que éstos consideran necesarios para su realización personal. En este sentido, forma parte central de la dimensión normativa del concepto de reconocimiento la identificación de las peticiones de los sujetos a modo de "imperativos":

la reproducción de la vida social se cumple bajo
el imperativo de un reconocimiento reciproco,
ya que los sujetos sólo pueden acceder a una
relación práctica consigo mismos si aprenden a
concebirse a partir de la perspectiva normativa
de sus compañeros de interacción, en tanto que
sus destinatarios sociales (HONNETH, 1992, p. 53).

Tal como se observa en esta cita, en su versión temprana del concepto de "reconocimiento", lo 
normativo y lo constitutivo se mezclan en una misma formulación. A su vez, tampoco queda del todo claro si la relación de reconocimiento debe ser entendida, como se deja ver en el pasaje citado, como relaciones de interacción entre sujetos individuales o, como también aludirá Honneth mediante su lectura de Mead, como membresía o participación social del sujeto en las expectativas institucionalizadas de un "Otro generalizado". Algunos años después, con ocasión de su debate con Nancy Fraser, Honneth revisará la estructura teórica de su concepto, planteando la necesidad de una distinción más cuidada de los niveles que aquí aparecian solapados. En esta nueva formulación Honneth le otorgará un primado indiscutible al sentido constitutivo de su concepto fundamental. La combinación teórica de "sociedad" y "subjetividad" en el concepto de reconocimiento puede asumir un contenido normativo porque este concepto es en primera medida el medio de configuración de ambos, de la sociedad y de la subjetividad.

Para determinar esta articulación, Honneth desarrolla el concepto de reconocimiento en dos direcciones, como "socialización moral del sujeto", y como "integración moral de la sociedad" (FRASER Y HONNETH, 2003, p. 205). La primera dirección del desarrollo del concepto de reconocimiento se sostiene en la tesis de que "todo sujeto humano depende esencialmente de un contexto de formas de interacción social regido por principios normativos de reconocimiento mutuo" (Ibíd., p. 205). La subjetividad consiste en tener "capacidades y necesidades específicas", y esta titularidad es un hecho social. En la medida en que estos movimientos corporales me son atribuidos como acciones, los sonidos emitidos interpretados como mis expresiones, y estos impulsos como mis propósitos, ser sujeto supone necesariamente ser reconocido en tanto tal. Sólo mediante ese reconocimiento me puedo percibir a mí mismo como un yo que, como diria Kant en referencia a la apercepción trascendental (pero en un sentido opuesto), "acompaña todas mis representaciones".

La segunda dirección del desarrollo del concepto de reconocimiento se sostiene en la tesis de que las sociedades son "estructuras ordenadas" (Ordungsgefüge) que "están en condiciones de garantizar relaciones fiables de reconocimiento mutuo en distintos niveles" (Ibid., p. 206). Por medio de la integración social, entendida como proceso de transformación de individuos en "miembros plenos", la sociedad produce sujetos: la sociedad es un contexto de relaciones en el que los hombres y mujeres, las ejecuciones prácticas y los objetos adquieren un status social y, de esta manera, son reconocidos como sujetos, acciones y productos. Ser reconocido implica necesariamente participación social. El reconocimiento recíproco entre sujetos individuales se despliega por lo tanto siempre ya entre miembros de una generalidad social. Para Honneth, la lógica del reconocimiento se da en la forma de una "dialéctica de lo general y lo particular": en la relación dialéctica entre la forma social general y su realización especifica. Ser reconocido como un sujeto facultado, como una acción con sentido, o como un producto útil, implica necesariamente ya una realización particular de una forma social general.

El despliegue teórico de esta dialéctica la acompañará Honneth mediante una lectura transversal de la filosofía hegeliana, desde los textos tempranos anteriores a la Fenomenología del espiritu hasta los Principios fundamentales de la filosofía del derecho. Tanto en los escritos de juventud de Jena, como en el Hegel maduro, Honneth identificará una perspectiva teóricosocial de fundamentación normativa que, a partir de una formulación precisa del concepto de reconocimiento, podrá dar cuenta de las condiciones de una teoría de la justicia anclada en un paradigma intersubjetivo. Lo que rescata Honneth del planteo de Hegel acerca de la cuestión del reconocimiento en sus múltiples apariciones es su identificación con una ontología social en la que se lo concibe como presupuesto o condición de posibilidad del proceso de formación de la razón humana. De las luchas por el reconocimiento que Hegel describe se extrae así la conclusión de que en la percepción del otro como sí mismo y del sí mismo como 
otro se constituye el espacio de las relaciones en el que podrá originarse la moralidad y la racionalidad de lo humano. En el movimiento del reconocimiento, dice Hegel, las conciencias adquieren reflexivamente el conocimiento de que son "como si mismas en otra conciencia" Asi se expresa, por ejemplo, en la siguiente formulación de sus borradores de 1803/04:

En el reconocimiento, la identidad deja de ser singularidad [...]. El reconocido lo es en tanto que inmediatamente valioso, por su ser, pero este ser es producido por el concepto: es ser reconocido. El hombre es necesariamente un ser reconocido y que reconoce. Esta necesidad es la suya propia [...]. En tanto que reconocer, él mismo es el movimiento y este movimiento (HEGEL, 1986b, p. 206).

En esta ocasión no nos detendremos en las especificidades de la lectura que propone Honneth en las distintas versiones en las que Hegel presenta su concepto de reconocimiento, a sabiendas que la elección de distintos momentos de la obra de Hegel involucra consecuencias teóricas de largo alcance. Tampoco nos ocuparemos de reconstruir los aspectos que Honneth distingue en su presentación de las transformaciones modernas del derecho (HONNETH, 2011), sino que quisiéramos referirnos más modestamente a un motivo específico mediante el cual Honneth vuelve a plantear esta dialéctica de lo general y lo particular en su teoria del reconocimiento, y de la que se derivan posibilidades conceptuales cuyo lugar y valor permanecen ocultos para una perspectiva que se mueva dentro de los límites de su conceptualidad.

La figura en cuestión aqui se presenta en un pasaje de los Principios de la filosofia del derecho (HEGEL, 1986C). Se trata de la transición desde la moralidad hacia la "eticidad" (Sittlichkeit). En §149, dice Hegel lo siguiente: "en el deber el individuo se libera y alcanza la libertad sustancial". Para Honneth, este pasaje resulta clave, puesto que da cuenta de dos sentidos de la idea de libertad ligados a la noción de aceptación de deberes pretendidamente "éticos". Desde un punto de vista negativo, la "liberación" (Befreiung) a la que hace alusión Hegel implica una exoneración de los puntos de vista particulares que limitan la libertad. Para Hegel estos puntos de vista pueden ser condensados en las "imágenes" de la libertad que ofrecen tanto el derecho subjetivo como la moral racional. En ambas imágenes lo que se pierde de vista es la infraestructura de condiciones sin las cuales el individuo no puede realizarse como voluntad libre. La ceguera acerca de la "normatividad de las relaciones sociales" en las que el individuo se encuentra situado lo conduce a un "torturante vacio" y a una experiencia de "indeterminación" que, según Hegel, es causa de sufrimiento. Es por eso que, como indica correctamente Honneth, para Hegel esta liberación en la aceptación del deber involucra un proceso de formación (Bildung) de la conciencia en la que ésta se libera a modo de "terapia" de las "patologías" que estas confusiones conceptuales han causado. En el pasaje citado Hegel sin embargo no sólo refiere a un sentido negativo en la interpretación de la liberación del individuo, como "exoneración de las dependencias ocultas", sino que le otorga un contenido positivo: el sujeto se libera para. Este segundo sentido del pasaje le otorga según Honneth la dimensión central a la expresión, puesto que conecta su perspectiva con una teoria de la justicia fundada en términos de intersubjetividad. Como ha sostenido Vladimir Safatle (2015, p. 287), con precisión, el modo en que Honneth artícula aqui subjetividad y sociedad a partir del anclaje del concepto de reconocimiento en una teoria de la intersubjetividad conlleva la consecuencia de una determinación de ese concepto, y de las estructuras relacionales que intenta pensar, que desatiende posibilidades interpretativas antagónicas, también inscriptas en su raiz hegeliana. ${ }^{3}$ La conquista que supone el proceso de la liberación del sujeto se coloca en los términos de una adquisición de reflexividad mediante la cual el individuo se integra en una "libertad sustancial". Como sabemos, esta 
idea sustancial de libertad Hegel la identifica con el contexto de hábitos y costumbres que representan las prácticas institucionalizadas en un espíritu objetivo o eticidad. La sociedad se nos presenta así, como en la introducción a los Principios de la filosofia del derecho, como sinónimo de "libertad realizada, el mundo del espiritu que se produce a sí mismo como una segunda naturaleza". El plus de reflexividad que gana el sujeto en este proceso de formación de la conciencia se plantea asi en los términos de un futuro anterior: en su liberación de sus formas naturales de existencia, el sujeto reconoce que siempre ya integra o participa de un "mundo espiritual" de interacciones, vale decir: de un orden normativo de reconocimiento o "segunda naturaleza", en el que su propia autorrealización personal se hace posible. La libertad sustancial se conquista por medio de la rememoración liberadora que da cuenta del estatuto social o, en los términos de Hegel, "ético", del sujeto.

\section{Ley y libertad}

Recientemente Christoph Menke (2018) ha propuesto una relectura de estos pasajes de la filosofía hegeliana en la que las relaciones entre justicia y libertad, sociedad y subjetividad, son analizadas desde una perspectiva relativamente desplazada que da cuenta de una propuesta novedosa de reactualización del legado de la Teoría Critica de la sociedad. Para ello, Menke propondrá una nueva manera de interpretar la "dialéctica de lo general y lo particular" a la que hacia alusión Honneth. Inspirándose en las reflexiones de Adorno (2010) acerca de los problemas de filosofía moral en el mundo contemporáneo, Menke subrayará la determinación procesual de esta dialéctica, poniendo de manifiesto así un enfoque crítico de toda deriva sustancialista del concepto de reconocimiento.

Veamos brevemente cómo interpreta Adorno esta dialéctica. Para comenzar, Adorno inscribe su discusión en su lectura de los textos más relevantes de la filosofía moral moderna. En la perspectiva adorniana, el acto de lectura de un texto filosófico no descansa en una mera exegética vacua de lo que el autor haya querido decir -en este sentido, su lectura no queda atada a una mera filología de la historia de la filosofia-, sino en una interpretación que, al detenerse en la letra del texto, logra revelar un "paralelogramo de fuerzas", desmintiendo sus pretensiones de clausura lógica. Desplegar el texto en sus tensiones íntimas, en sus fricciones y en sus imposibilidades es la tarea que le corresponde a la lectura, haciendo del texto así un sismógrafo de conflictos y problemas concretos de la experiencia histórica de los agentes que actúan en el mundo social. Dado que "las categorías sociales se inmiscuyen en lo más profundo de las categorias de la filosofía moral" (Ibid., p. 258), la lectura de un texto filosófico, su interpretación "con lentes de aumento" en sus desplazamientos y condensaciones, implica también una forma de la crítica social.

En este contexto, Adorno encuentra en la "dialéctica de lo general y lo particular" el núcleo más fundamental de toda filosofía moral moderna. Ella describe la relación entre "los intereses particulares, los comportamientos de los hombres individuales, y lo general que se le antepone". De esta forma, las distintas perspectivas de filosofia moral han procurado mediar ambas instancias o bien presuponiendo la posibilidad de una subsunción de lo particular en lo general, o bien, a la inversa, concibiendo a lo general como el resultado de una agregación de particularidades, definidas de antemano como unidades idénticas a sí mismas. Mientras que en el primer caso la filosofía procede a legitimar modelos de soberanía política absoluta, en la segunda alternativa recae en un atomismo social. En cualquiera de los casos, lo que se anula es la misma dialéctica entre ambas instancias, abriendo así el campo para la formulación de todos los problemas de la filosofía práctica. A la vista de esta condición problemática, dice Adorno, una interpretación dialéctica de esta dialéctica consistiría en interrumpir el presupuesto de que las oposiciones que la desgarran estén condicionadas por un horizonte de resolubilidad exterior a su despliegue. Al sustraerse a esta condicionalidad lógica, se vuelve posible describirla sin falseamientos, uno 
de los cuales es la presuposición de que entre ambos términos es posible establecer una "relación bien balanceada" de equilibrio simétrico. Adorno sostiene que su principal determinación viene marcada por una "doble imposibilidad". Ninguno de los términos logra realizarse sin ejercerviolencia sobre el otro y sin asumir motivos represivos que desmienten sus pretensiones de verdad. Adorno se acerca esta doble imposibilidad ubicándola en una constelación en la que intervienen distintas polaridades conceptuales, como la que se expresa en la antinomia de la figura kantiana de la "causalidad de la libertad", y niveles de análisis heterogéneos, como la contraposición entre la idea de justicia -sostenida por distintas expresiones filosóficas de la ética de la intención-y las distintas concepciones morales del bien -subrayadas por las asi llamadas éticas de la responsabilidad.

Cuando se revisa el marco en el que se inscriben las indagaciones hegelianas acerca del problema de la libertad, se puede observar que ellas parten de una visión crítica acerca de la identificación operada por Kant con la idea de autonomía moral. En este contexto, Menke nos propone (2018, p. 79), volver a leer $\$ 149$ de los Principios de la filosofia del derecho, puesto que, según su hipótesis, pueden descubrirse tensiones semánticas descuidadas de gran significación para la Teoría Crítica contemporánea. Cuando Hegel sostiene que "en el deber el individuo se libera y alcanza la libertad sustancial", se afirman dos proposiciones contrapuestas. En la primera parte de la sentencia, "el individuo se libera", lo que se identifica es un contenido activo del sujeto, un acto, que Hegel denomina "liberación", y que no puede sino ser entendida como un devenir. En este sentido, la libertad como proceso de liberación supone la negación de un estado de sujeción que le antecede. La libertad contiene una historia, y ella se evidencia ontológicamente en su modo de ser procesual. Para Hegel, por el contrario, la identificación kantiana de la libertad como autonomía o auto-legislación se desentiende de esta negatividad inmanente a la libertad como acto o promesa, determinando a esta ya no como devenir sino como positividad.
Podemos reconocer esta crítica de la idea de auto-legislación en los escritos previos a la Fenomenología del espiritu. Para eljoven Hegel, que suscribia a las criticas de Schiller a la moral racional en De la gracia y la dignidad, la idea kantiana de autonomía, al ser identificada con el fenómeno de la internalización de la autoridad, no es sinónimo de libertad sino de sujeción por otros medios. En este sentido, Kant fracasa en resolver el problema planteado ya por Rousseau de cómo conciliar la libertad con la obediencia a la ley. La autolegislación del sujeto no supera ni la obediencia ni la sujeción ante la ley. En "El espiritu del cristianismo y su destino" [1798-1800], por ejemplo, presenta Hegel su crítica en los siguientes términos:

Entre los shamanos de los Tunguses, los prelados europeos que gobiernan en la Iglesia y en el Estado y los puritanos, por una parte, y el hombre que obedece el mandamiento de su propio deber, por otra, la diferencia no está en que los primeros estén en la servidumbre y este último sea libre, sino en que los primeros tienen a su Señor fuera de sí, mientras que el segundo lo lleva dentro de sí mismo, siendo al mismo tiempo su propio esclavo (HEGEL, 1986a, p. 150).

En la recuperación de la paradoja de la "obediencia voluntaria", Hegel contrapone dos instancias, el soberano que legisla y el sujeto que se somete. Exterior al sujeto o interiorizada, heterónoma o autónoma, la ley y su vínculo con la libertad se plantea en Kant en los términos de una oposición: "Puesto que las leyes son unificaciones de opuestos en un concepto que les deja su carácter de opuestos, y puesto que el concepto mismo consiste en la oposición contra la realidad, el concepto expresa un Debe". Por el contrario, para entender correctamente el estatuto de la ley, se vuelve necesario identificarlo no con un Deber sino con la realidad de un Ser. El modo de ser de la ley, su existencia, "es la sintesis de sujeto y objeto en la cual sujeto y objeto han perdido su oposición".

Detrás de esta identificación del ser de lo normativo con una "sintesis" se mueve una pulsión ética que Hegel mantuvo desde temprano orientada hacia una forma de relación del sujeto consigo mismo que no involucre sujeción ni violencia. Una relación libre del sujeto consigo mismo en la que éste ya no haga de sí mismo 
su propio esclavo sino que sea el agente de su autorrealización personal. Ahora bien, para Hegel esta pulsión no puede ser pensada como la motivación abstracta de una crítica exterior, vale decir: en la forma de un "Deber" que se le imponga desde afuera, puesto que de otro modo recaería en los déficits del trascendentalismo moral que su teoria de lo normativo viene a superar; sino por el contrario que esta crítica integra, o dicho de otra manera: le es interior a la vida, constituyendo así el modo de ser de lo normativo. Precisamente esto es lo que está en juego en la primera parte de parágrafo 149 de los Principios de la filosofía del derecho cuando Hegel identifica a la libertad con la negatividad de un proceso de liberación que en su definición como acto no tiene fin.

Sin embargo la recomendación de Hegel de interpretar el modo de existencia de lo normativo como un Ser también nos permite entender la segunda parte del parágrafo citado, vale decir: la identificación de la libertad ya no como proceso sino como fin al que ese devenir conduce, con un estado en el que el concepto y la existencia de la libertad se identifican en una unidad "sustancial". En la libertad sustancial a la que Hegel hace alusión, sujeto y objeto se integran en la "sintesis" de la ley, superando de esta manera las oposiciones que marcaban la antinomia de Kant. El sujeto no se da a si mismo la ley, sino que él mismo es uno con ella. La consecuencia de esta disolución, no obstante, es que esta sintesis suprime injustificadamente uno de los términos que constituian el problema a resolver, a saber: el vínculo entre ley y libertad. Aun cuando no sea la forma de sujeción que se expresaba en la figura de la auto-legislación, leida como obediencia al amo interior, en la libertad sustancializada en una segunda naturaleza donde sujeto y ley coinciden inmediatamente, el sujeto se somete a una forma de no libertad que involucra disciplinamiento y normalización.

\section{Lo general y lo particular}

Que alguien o algo sea reconocido significa que esa persona, o sus acciones y productos sean vistos como elementos de una praxis social. La lógica del reconocimiento es la dialéctica de lo general y lo particular. Lo reconocido es una particularidad de una generalidad. Precisamente por ello, como sostiene la lectura de Honneth, en el reconocimiento los sujetos conquistan su libertad. Al reconocerse como miembros plenos de una generalidad social, los individuos adquieren así dos facultades: 1) un poder de reflexión o "Derecho" que les habilita a relacionarse consigo mismos como sujetos, descubriendo dimensiones de su personalidad que ahora pueden ser identificadas como "cualidades y capacidades" legitimas de su identidad, y por lo tanto exigir normativamente que sean reconocidas cuando esto no suceda en una "praxis de interpretación social dominante"; y, al mismo tiempo, 2) un poder de decisión o "derecho" que los titula para discutir públicamente de qué forma quieren vivir en sociedad, integrando así los procesos de formación politica de la voluntad colectiva. Para un concepto tradicional de eticidad que lo reconocido sea una particularidad de una generalidad implica que lo particular debe ser pensado como una mera repetición sin diferencia en la realización de lo general social. Por el contrario, para un moderno concepto de eticidad democrática, que lo reconocido sea una particularidad de una generalidad implica que lo reconocido es una versión singular de lo general social: una especíica, individualizada y divergente realización de esa generalidad.

Esta dialéctica, correctamente interpretada, permite comprender de un nuevo modo la reflexividad contenida en las prácticas modernas de reconocimiento. Si en cada individuación se pone en acto un devenir reflexivo del reconocimiento social, lo que queda abierto es la determinación de la forma en la que se despliega la lógica de lo general y lo particular, vale decir: la relación en la que los individuos integran la vida social. Según el moderno concepto de eticidad que sostiene Honneth, la reflexividad del reconocimiento reconoce la dependencia simultánea de lo general social de cada particular individual. Devenir reflexivo significa aqui descubrir de forma liberadora la necesidad de la generalidad social de la 
individuación. Ahora bien, el contenido de esta liberación reflexiva como despliegue de la dialéctica de lo general y lo particular en el reconocimiento no es unívoco. Como en las dos acepciones del concepto hegeliano de libertad, a saber: como liberación y como libertad sustantiva, como devenir o como ser, en ambas posibilidades asistimos a la transformación de la lógica social del reconocimiento. Pero cada una de ellas plantea exigencias normativas divergentes.

Podemos entender esta liberación del reconocimiento como transformación de la lógica de lo general y lo particular en la modificación de las relaciones de dependencia de cada uno de los términos, sopesando su contribución relativa en la relación de la participación social. La reflexividad de las prácticas de reconocimiento aquí es sinónimo de un uso del "exceso de validez de los principios de reconocimiento contra la concreción de su interpretación social" (FRASER Y HONNETH, 2003). El resultado de esta apropiación liberadora del exceso de validez es la transformación de un equilibrio de fuerzas, y su reestructuración en una nueva distribución de las partes en un "reconocimiento ampliado" que contribuye a lo que Hegel denominaba libertad sustancial. En la medida en que esta reflexividad propone nuevas formas de interpretación de principios normativos existentes sin que estas transformaciones supongan una suspensión de la validez de esos principios, podemos denominar también a este proceso lucha interna por el reconocmiento (RANCIÉRE Y HONNETH, 2016, p. 105).

Pero también podemos entender esta liberación del reconocimiento en el otro sentido del genitivo, vale decir, en su sentido negativo. La reflexión liberadora que transforma las relaciones entre los términos de la dialéctica ya no es sinónimo de un nuevo uso o interpretación de los principios normativos, sino de la suspensión radical de la validez de la lógica social constitutiva de lo general y lo particular. El resultado de esta suspensión liberadora de la validez es nada más y nada menos que la interrupción y la limitación de la relación de la participación social. Pero, como en la interpretación procesual de la liberación como acto que nos ofrecía Hegel, esta suspensión nunca puede ser concluyente, sino que ella siempre debe empezar de nuevo, en una repetición sin fin que la inscribe como promesa.

\section{A modo de conclusión}

El doble sentido del motivo de la "liberación del reconocimiento" que hemos diferenciado en las distintas lecturas de la filosofía de Hegel presupone entonces una operación conceptual fundamental para la posibilidad de su correcto abordaje. Nos referimos a la liberación teórica de los potenciales del concepto de reconocimiento de sus interpretaciones restringidas a una de las acepciones particulares de su dinámica. Liberar al concepto de reconocimiento significa aquí visibilizar su heterogeneidad constitutiva, el exceso que subvierte los intentos de su clausura. A los fines de que no sea falseado, el concepto de reconocimiento por lo tanto sólo puede ser interpretado dialécticamente, a condición de asumir esa dialéctica sin presupuestos ideales exteriores que la condicionen. Esta lectura materialista de la dialéctica permite abrir el concepto de reconocimiento a su alteridad inmanente, transformándolo en una unidad internamente contradictoria.

Como en la tensión que hemos identificado en el motivo de una "liberación del reconocimiento", aqui también la liberación de la negatividad que constituye al concepto da lugar a un plus de reflexividad. El reconocimiento de la "doble imposibilidad" que marca la relación entre la sociedad y la subjetividad, la ley y la libertad, lo generaly lo particular, es, finalmente, la posibilidad de un saber acerca de la fragilidad de los vínculos humanos y de la indeterminación constitutiva de las identidades forjadas en esos procesos. En este sentido, la Teoria Crítica contemporánea puede saberse continuadora del programa teórico y práctico con el que fue pensada originalmente ya en la primera mitad del siglo pasado, a saber: orientándose de manera tal que sus reflexiones no contribuyan a que "algo funcione mejor", sino hacia la posibilidad de una emancipación de lo existente. 


\section{Bibliografía}

ADORNO, Theodor. Probleme der Moralphilosophie, Frankfurt: Suhrkamp, 2010.

FRASER, Nancy y HONNETH, Axel. Umverteilung oder Anerkennung? Eine politisch-philosophische Kontroverse, Frankfurt: Suhrkamp, 2003.

HEGEL, Georg W. F. Frühe Schriften. Werke 1, Frankfurt: Suhrkamp, 1986a.

HEGEL, Georg W. F. Jenaer Schriften 1801-1807. Werke 2, Frankfurt: Suhrkamp, 1986b.

HEGEL, Georg W. F. Grundlinien der Philosophie des Rechts. Werke 7, Frankfurt: Suhrkamp, 1986c.

HONNETH, Axel. Kampfum Anerkennung: zur moralischen Grammatik sozialer Konflikte, Frankfurt: Suhrkamp, 1992.

HONNETH, Axel. Das Recht der Freiheit: grundriß einer demokratischen Sittlichkeit, Frankfurt: Suhrkamp, 2011.

HONNETH, Axel. Anerkennung: eine europäische Ideengeschichte, Frankfurt: Suhrkamp, 2018.

MENKE, Christoph. Autonomie und Befreiung, Frankfurt: Suhrkamp, 2018.

RANCIÉRE, Jacques; HONNETH, Axel. Recognition or Disagreement: a critical encounter on the politics of freedom, equality, and identity, New York: Columbia University Press, 2016.

SAFATLE, Vladimir. O circuito dos afetos: corpos políticos, desamparo e o fim do indivíduo, São Paulo: Cosac Naify, 2015

\section{Agustín Lucas Prestifilippo}

Doctor en Ciencias Sociales (UBA), Magister en Estudios Literarios (UBA) y Sociólogo por la Universidad de Buenos Aires. Se desempeña como docente de grado y de postgrado en la misma universidad. Es autor del libro El lenguaje del sufrimiento. Estética y política en la teoria social de Theodor Adorno (Prometeo, 2018) y ha publicado numerosos artículos sobre teoria social, filosofía y crítica cultural. Sus principales áreas de investigación son: la Teoría Critica de la Escuela de Frankfurt, la filosofía estética, los estudios literarios y la sociología del neoliberalismo.

\section{Fábio Caires Correia}

Doutor em Filosofia pela PUCRS. Professor Substituto no Colegiado de Filosofia da Universidade Federal do Tocantins (UFT).

\section{Dirección:}

Agustín Lucas Prestifilippo

Universidad de Buenos Aires

Viamonte 430, C1053

Ciudad Autónoma de Buenos Aires, CABA, Argentina

Fábio Caires Correia

Pontificia Universidade Católica do Rio Grande do Sul Av. Ipiranga, 6681

Partenon, 90619-900

Porto Alegre, RS, Brasil 